This item was submitted to Loughborough's Research Repository by the author.

Items in Figshare are protected by copyright, with all rights reserved, unless otherwise indicated.

\title{
External sulphate attack of sprayed mortars with sulphate-resisting cement: Influence of accelerator and age of exposition
}

PLEASE CITE THE PUBLISHED VERSION

https://doi.org/10.1016/j.cemconcomp.2020.103614

PUBLISHER

Elsevier

VERSION

AM (Accepted Manuscript)

\section{PUBLISHER STATEMENT}

This paper was accepted for publication in the journal Cement and Concrete Composites and the definitive published version is available at https://doi.org/10.1016/j.cemconcomp.2020.103614

LICENCE

CC BY-NC-ND 4.0

\section{REPOSITORY RECORD}

Herrera-Mesen, C, RP Salvador, T Ikumi, Sergio Cavalaro, and A Aguado. 2020. "External Sulphate Attack of Sprayed Mortars with Sulphate-resisting Cement: Influence of Accelerator and Age of Exposition". Loughborough University. https://hdl.handle.net/2134/13105508.v1. 


\section{External sulphate attack of sprayed mortars with sulphate-resisting}

\section{2 cement: influence of accelerator and age of exposition}

3 C. Herrera-Mesen ${ }^{\text {a }, ~}{ }^{1}$, R.P. Salvador ${ }^{\text {b }}$, T.Ikumi ${ }^{\text {a }}$, S.H.P. Cavalaro ${ }^{\text {c, }}{ }^{2}$, A. Aguado ${ }^{\text {a }}$

$4 \quad{ }^{a}$ Department of Civil and Environmental Engineering, Barcelona Tech, Polytechnic

5 University of Catalonia, UPC, Jordi Girona 1-3, 08034, Barcelona, Spain.

6 b Department of Civil Engineering, São Judas Tadeu University, 546 Taquari St., 03166-000,

7 São Paulo, Brazil

$8{ }^{\mathrm{c}}$ School of Architecture, Building and Civil Engineering, Loughborough University,

9 Leicestershire, LE11 3TU, UK

\section{ABSTRACT}

13 This work evaluates the influence of the accelerator type, the cement type and age of

14 exposure on the degradation mechanism and the durability of sprayed mortars subjected to

15 external sulphate attack (ESA). Cores and prisms were extracted from panels sprayed with 8

16 mortar compositions (with 2 sulphate-resisting cement types and 4 setting accelerators) and

17 then exposed to a sulphate solution at the ages of 7 or 28 days for 400 days. The evolution of

18 the ESA was assessed through XRD, SEM, compressive strength, dimensional variation and

19 ultrasonic pulse velocity. Results show that alkaline accelerators increase drastically the

20 vulnerability of the matrix to the ESA. The degradation is enhanced by the higher solubility

21 of aluminate phases and the increased formation of expansive phases. Results reveal that the

22 use of sulphate-resisting cement might not suffice to mitigate severe material degradation.

24 Keywords: Durability, External Sulphate Attack, Accelerators, Sprayed Materials, Sulphate-

25 Resisting Cement. 
27 Corresponding authors.

28 E-mail addresses: ${ }^{1}$ carlos.manuel.herrera@.upc.edu (C.Herrera-Mesen);

29 22S.Cavalaro@lboro.ac.uk (S Cavalaro).

\section{$31 \quad$ 1. Introduction}

Recent developments in set accelerators and spraying equipment have prompted the use of sprayed mixes with Portland cement in underground and other ground contention applications. The construction process consists of spraying a cementitious mix that consolidates upon reaching the substrate [1]. The mix must have adequate consistency and setting time to enable the build-up of layers with the desired thicknesses. Accelerators work to reduce the setting times and increase the early strength of the matrix, thus enabling the faster layer deposition and execution of challenging overhead elements. The accelerators also alter the matrix short- and long-term hydration, microstructure and properties [2-4].

Immediately after spraying, the material remains in direct contact with the surrounding soil and underground water, which may contain aggressive agents such as sulphates. As they penetrate through the interconnected porous network of the matrix, sulphates can react with aluminate phases in the matrix to form expansive compounds (secondary ettringtite or secondary gypsum) and cause damage in a process known as external sulphate attack (ESA). Secundary ettringite formation in small pores $(<50 \mathrm{~nm})$ has been identified according to [5-6] as the main force to weakening the matrix due the cristallization in the pore. Other types can be adressed as gypsum secondary gypsum or thaumasite formation, aluminathe phases can react with $\mathrm{Ca} 2+$ or $\mathrm{Na}+$ $[6,7]$ To mitigate the consequences of the attack, most standards and recommendations rely on the specification of sulphate-resisting (SR) cements characterised by a limited C3A content (generally below $5 \%$ by cement weight [6-7]). 
54 Nevertheless, this countermeasure only considers aluminates in the cement, falling short to

55 account for the influence of aluminates coming from other sources, like the accelerators. It

56 also does not account for the higher interconnected porosity induced by the spraying process

57 and the very early exposure to sulphates that could favour the sulphate ingress and the ESA in

58 comparison with conventionally cast matrices.

60 The lack of specific considerations might be a consequence of the limited knowledge about

61 the impact of the spraying process with accelerators in the durability to ESA. To illustrate it,

62 Table 1 summarises the variables and experimental methods from studies published in the last

6320 years about the ESA in sprayed or cast mixes with and without accelerators.

64

Table 1. Recent studies about the ESA in matrices with Portland cement.

\begin{tabular}{|c|c|c|c|c|c|c|c|c|c|c|c|c|c|}
\hline & \multicolumn{10}{|c|}{ References } & \multirow{2}{*}{$\begin{array}{l}\text { This } \\
\text { work }\end{array}$} \\
\hline & & & [10] & [11] & [12] & [13] & [14] & [15] & [16] & [17] & [18] & [19] & \\
\hline \multirow{8}{*}{$\frac{\frac{\tilde{d}}{0}}{\frac{\pi}{\pi}}$} & \multicolumn{2}{|c|}{$\begin{array}{l}\text { Before exposition } \\
\text { (days) }\end{array}$} & 57 & 57 & 15 & 14 & 14 & 14 & 57 & 28 & - & 7 & $\begin{array}{c}7 \text { and } \\
28\end{array}$ \\
\hline & \multirow{2}{*}{ Type of mix } & Cast & $\bullet$ & & - & - & $\bullet$ & $\bullet$ & $\bullet$ & $\bullet$ & $\bullet$ & $\bullet$ & $\cdot$ \\
\hline & & Spray & $\bullet$ & $\bullet$ & & & & & & & & & $\bullet$ \\
\hline & \multirow{3}{*}{ Cement } & $\mathrm{I}$ & $\bullet$ & $\bullet$ & $\bullet$ & & & & & & & & $\bullet$ \\
\hline & & II & & $\bullet$ & $\bullet$ & - & & & - & $\bullet$ & - & & - \\
\hline & & $\mathrm{SR}^{\mathrm{a}}$ & X & X & $V$ & $V$ & X & $X$ & $V$ & $\mathrm{X}$ & $V$ & $V$ & $V$ \\
\hline & \multirow{2}{*}{ Accelerators $^{\mathrm{b}}$} & $\mathrm{AF}$ & - & - & & & & & & & & & - \\
\hline & & AR & $\bullet$ & $\bullet$ & & & & & & & & & $\bullet$ \\
\hline \multirow{5}{*}{ 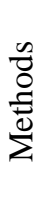 } & \multicolumn{2}{|c|}{ Dimension stability } & - & $\bullet$ & & & & - & - & & - & - & $\bullet$ \\
\hline & \multicolumn{2}{|c|}{ Velocity of US } & & & & & & & & & & & $\bullet$ \\
\hline & \multicolumn{2}{|c|}{ Phase composition } & $\bullet$ & $\bullet$ & $\bullet$ & & $\bullet$ & & $\bullet$ & $\bullet$ & $\bullet$ & $\bullet$ & $\bullet$ \\
\hline & \multicolumn{2}{|c|}{ SEM } & $\bullet$ & $\bullet$ & $\bullet$ & & $\bullet$ & - & • & & $\bullet$ & & • \\
\hline & \multicolumn{2}{|c|}{ Mechanical tests } & & & - & & & - & & - & & & - \\
\hline
\end{tabular}

a: sulphate-resisting according to [8,9]

b: alkali-free(AF) or alkaline (AR)

67 Notice that only [7] and [8] evaluate the influence of accelerators on the durability of sprayed

68 mixes exposed to sulphates. Their findings suggest a link between the accelerators and the

69 increase in the degradation induced by the ESA. However, none of these studies evaluates the

70 impact of the age of exposition to the sulphates, assuming a time that might not represent real

71 applications. More importantly, they do not assess the performance of mixes with SR cement, 
which is essential to elucidate if the recommendation found in codes to mitigate the ESA also

73 suffice for sprayed mixes with the accelerator. This critical gap in knowledge has potentially

74 negative practical repercussions.

The objective of this work is to evaluate how the chemical composition of accelerators and the age of exposition to sulphates affect the degradation mechanism of sprayed mixes with SR cements subjected to ESA. In total, 8 mortar compositions were sprayed in laboratory conditions with 2 SR cement and 4 set accelerators. Cores and prisms were extracted and exposed to a sulphate solution at 7 and 28 days since production for 400 days. Evolution of phases, microstructure and macroscopic behaviour were characterized.

Results complement the limited literature on the behaviour sprayed mixes with accelerator subjected to ESA. Moreover, findings shed light on understanding the ESA consequences in sprayed mixes with SR cement at micro- and macro-structural levels depending on the accelerator type. Observations derived here might guide the selection of materials to enhance the durability of sprayed structures and help steer the definition of more appropriate recommendations in standards to mitigate the ESA in such application.

\section{Experimental Program}

2.1.

\section{Materials}

Mortar mixes contained either Cement I 52.5R (CEM I) or Cement II/A-L 42.5 R (CEM II) with $11.3 \%$ of limestone filler by cement weight (bcw). The former is employed in sprayed mixes in Asia and America [2,3], whereas the latter is widely used in Europe. Table 2 summarises the phase and chemical compositions of the cement determined by quantitative

98 XRD and XRF spectrometry, respectively. Both cements comply with the requirements 99 described in [20] and are SR according to [8,9]. 
101 A limestone aggregate $\left(>99 \% \mathrm{CaCO}_{3}\right)$ with a particle density of $2.32 \mathrm{~g} / \mathrm{cm}^{3}$, water absorption

102 of $5.46 \%$ was used. The particle size distribution of the aggregate rages from $0 \mathrm{~mm}$ to 1.25

$103 \mathrm{~mm}$, which is limited by the spraying equipment used in the experimental programme.

104 Distilled water and a superplasticiser based on a polycarboxylate solution (34\% solid content)

105 were employed.

106

107 To represent the typical types in tunnelling applications, 2 alkali-free accelerators

108 (AF060 and AF040), named because of the $\mathrm{Al}_{2} \mathrm{O}_{3} / \mathrm{SO}_{4}{ }^{2-}$ molar ratio and based on aqueous

109 solutions of aluminium sulphate and 2 alkaline accelerators (AR130 and AR080) named

110 because of the $\mathrm{Al}_{2} \mathrm{O}_{3} / \mathrm{Na}_{2} \mathrm{O}$ molar ratio and based on aqueous solutions of sodium aluminate

111 were chosen. Table 3 shows the main characteristics of these accelerators according to the

112 supplier.

113

114 Table 2. Phase and chemical compositions of cement.

\begin{tabular}{|c|c|c|c|c|c|}
\hline \multicolumn{3}{|c|}{ Phase Composition (\%) } & \multicolumn{3}{|c|}{ Chemical Composition (\%) } \\
\hline & CEM I & CEM II & & CEM I & CEM II \\
\hline $\mathrm{C}_{3} \mathrm{~S}$ & 58.3 & 51.7 & $\mathrm{CaO}$ & 62.6 & 62.5 \\
\hline $\mathrm{C}_{2} \mathrm{~S}$ & 11.2 & 6.7 & $\mathrm{SiO}_{2}$ & 19.9 & 17.6 \\
\hline $\mathrm{C}_{4} \mathrm{AF}$ & 13.4 & 14.8 & $\mathrm{Al}_{2} \mathrm{O}_{3}$ & 4.7 & 4.0 \\
\hline $\mathrm{C}_{3} \mathrm{~A}_{\mathrm{c}}$ & 4.1 & 2.9 & $\mathrm{Fe}_{2} \mathrm{O}_{3}$ & 3.3 & 3.5 \\
\hline $\mathrm{C}_{3} \mathrm{~A}_{\mathrm{o}}$ & 0.6 & 0.7 & $\mathrm{SO}_{3}$ & 3.5 & 3.2 \\
\hline $\mathrm{CaO}$ & 1.1 & 1.2 & $\mathrm{MgO}$ & 1.9 & 1.7 \\
\hline $\mathrm{Ca}(\mathrm{OH})_{2}$ & 1.7 & 0.7 & $\mathrm{~K}_{2} \mathrm{O}$ & 1.0 & 0.8 \\
\hline $\mathrm{CaCO}_{3}$ & 1.9 & 11.3 & $\mathrm{TiO}_{2}$ & 0.2 & 0.2 \\
\hline $\mathrm{CaSO}_{4} \cdot 2 \mathrm{H}_{2} \mathrm{O}$ & 2.1 & 0.7 & $\mathrm{P}_{2} \mathrm{O}_{5}$ & 0.1 & 0.1 \\
\hline $\mathrm{CaSO}_{4} \cdot 0.5 \mathrm{H}_{2} \mathrm{O}$ & 4.4 & 5.3 & LOI & 2.9 & 6.4 \\
\hline $\mathrm{K}_{2} \mathrm{SO}_{4}$ & - & 0.5 & & & \\
\hline $\mathrm{K}_{2} \cdot \mathrm{Ca}(\mathrm{SO} 4)_{2} \cdot \mathrm{H}_{2} \mathrm{O}$ & 1.1 & - & & & \\
\hline $\mathrm{MgO}$ & - & 0.6 & & & \\
\hline $\mathrm{MgCO}_{3}$ & - & 3.1 & & & \\
\hline Total & 100.0 & 100.0 & Total & 100.0 & 100.0 \\
\hline
\end{tabular}

115

116 Table 3. Characteristics of accelerators.

\begin{tabular}{ccccc}
\hline Characteristic & AF060 & AF040 & AR130 & AR080 \\
\hline Solid content & 48.0 & 68.5 & 43.0 & 61.9 \\
$\mathrm{Al}_{2} \mathrm{O}_{3}$ content $(\%)$ & 13.5 & 12.0 & 24.0 & 16.5 \\
$\mathrm{SO}_{4}{ }^{2-}$ content $(\%)$ & 21.0 & 29.0 & - & - \\
$\mathrm{Na}_{2} \mathrm{O}$ content $(\%)$ & - & - & 19.0 & 19.5
\end{tabular}


$\mathrm{pH}$ at $20^{\circ} \mathrm{C}$

$\mathrm{Al}_{2} \mathrm{O}_{3} / \mathrm{SO}_{4}{ }^{2-}$ molar ratio

$\mathrm{Al}_{2} \mathrm{O}_{3} / \mathrm{Na}_{2} \mathrm{O}$ molar ratio
3.1

0.6

2.2

0.4

$-$
12.0

1.3
12.5

0.8
117

118

119

120 Since the size of the aggregate does not play a key role in the chemical processes involved in 2.2.

121 the ESA, results obtained here might be taken as a reference of the trend expected for sprayed

122 ettringite ( $\mathrm{SO}_{4}{ }^{2-}$ consumed by $\mathrm{AFt}$ formation). 


$$
\text { Final } \frac{C_{3} A}{\mathrm{SO}_{3}}=\frac{C_{3} A_{\text {cement }}}{S_{4}^{-2} \text { cement }+S_{4}^{-2} \text { accelerator }-S_{4}^{-2} \text { consumed by accelerator }}
$$

145 The mixing process was performed in a planetary mixer type $65 / 2 \mathrm{~K}-3$ with 150 and $40 \mathrm{rpm}$

146 paddle and planetary rotations, respectively. First, all the cement and 90\% of the water were

147 mixed for $240 \mathrm{~s}$. Then, the superplasticizer was added with the remaining water and

148 homogenized for 240 s. Finally, the aggregate was added and mixed for 300 s. After the

149 mixing process, mortars were kept for $1 \mathrm{~h}$ at $20{ }^{\circ} \mathrm{C}$ until the spraying process. This procedure,

150 also adopted by $[3,21,22]$, intends to reproduce the typical field conditions as concrete must

151 be transported from the batching plant to the jobsite before spraying takes place.

152

153 Table 4. Chemical composition of sprayed mortars.

\begin{tabular}{|c|c|c|c|c|c|c|c|}
\hline \multirow[b]{2}{*}{ Name } & \multicolumn{7}{|c|}{ Composition (mmol /g cement) } \\
\hline & $\begin{array}{c}\text { Total } \\
\mathrm{SO}_{4}^{-2} \text { in } \\
\text { cement }\end{array}$ & $\begin{array}{c}\mathrm{Al} \text { in } \\
\text { accele. }^{\mathrm{a}}\end{array}$ & $\begin{array}{l}\mathrm{SO}_{4}^{2-} \text { in } \\
\text { acceler. }\end{array}$ & $\begin{array}{c}\mathrm{AFt} \\
\text { formed }^{\mathrm{b}}\end{array}$ & $\begin{array}{c}\mathrm{SO}_{4}{ }^{2-} \\
\text { consumed } \\
\text { by } \mathrm{AFt} \\
\text { formation } \\
\mathrm{C}\end{array}$ & $\begin{array}{c}\mathrm{SO}_{4}^{-2} \\
\text { left }\end{array}$ & $\begin{array}{c}\text { Final } \\
\mathrm{C}_{3} \mathrm{~A} / \mathrm{SO}_{3}\end{array}$ \\
\hline CI_REF ${ }^{(\mathrm{d})}$ & 0,44 & - & - & - & - & 0,44 & 0.59 \\
\hline CI_AF060_5\% & 0.44 & 0.13 & 0.11 & 0.07 & 0.20 & 0.35 & 0.73 \\
\hline CI_AF040_5\% & 0.44 & 0.12 & 0.15 & 0.06 & 0.18 & 0.26 & 0.63 \\
\hline CI_AR130_3\% & 0.44 & 0.14 & - & 0.07 & 0.21 & 0.23 & 1.13 \\
\hline CI_AR080_3\% & 0.44 & 0.10 & - & 0.05 & 0.15 & 0.29 & 0.90 \\
\hline CII_REF ${ }^{(\mathrm{d})}$ & 0.40 & - & - & - & - & 0.40 & 0.44 \\
\hline CII_AF060_5\% & 0.40 & 0.13 & 0.11 & 0.07 & 0.20 & 0.31 & 0.56 \\
\hline CII_AR080_3\% & 0.40 & 0.10 & - & 0.05 & 0.15 & 0.25 & 0.70 \\
\hline
\end{tabular}

${ }^{\mathrm{a}} \mathrm{Al}$ corresponds to $\mathrm{Al} 3+$ and $[\mathrm{Al}(\mathrm{OH}) 4]$ - in alkali-free and alkaline accelerators, respectively.

${ }^{\mathrm{b}} \mathrm{AFt}$ phase formed by the accelerator.

2.3. ${ }^{\mathrm{C}}$ Corresponds to the $\mathrm{SO}_{4}{ }^{-2}$ consum during the formation of the Aft phase.

${ }^{\mathrm{d}}$ Not sprayed.

\section{Spraying process}

157 The wet-mix spraying process is the most commonly used in underground construction

158 around the world [2] and was selected for this experimental programme. The spraying 
happened inside a climatic chamber at $20{ }^{\circ} \mathrm{C}$ and $90 \%$ relative humidity. The mortar was

160 sprayed in metallic panels forming a $45^{\circ}$ angle with the horizontal plane and placed inside the

161 climatic chamber shown in Figure 1.a. The dimensions (see Figure 1.b) and spraying of the

162 panels were based on [23].

163

164 The equipment used to spray the mortars in the laboratory (see Figure 1.c) is a small-scale

165 version of the setup found in previous research [2] and underground construction with

166 concrete. The mortar was pumped by the UP-Pictor screw pump (Fig.1.c item \#1) operating at

1676 bar of pressure provided by 3 HP air compressor. The screw pump was chosen for its

168 constant flow and absence of pulsation effect.

169

170 Figure 1. (a) Arrangement of panels inside the climatic chamber, (b) dimensions of the

171 metallic panels, (c) spraying equipment in laboratory conditions and (d) spray gun.

172

173 The material moved through the hose (Fig.1.c item \#2) and entered the spray gun (Fig.1.c

174 item \#3) through the main entrance (Fig 1.d item \#7). Compressed air (Fig 1.d item \#8) and

175 accelerators (Fig 1.d item \#9) were pre-mixed in a small chamber within the spray gun

176 (Figure 1.d item \#10) and, then, homogenised with the mortar inside the nozzle (Figure 1.d

177 item \#11). The resulting mix exited the nozzle at high speed and was sprayed onto the

178 metallic panels.

179

180 The accelerators (Fig.1.c item \#4) were dosed by an air-operated diaphragm pump (Fig1.c.

181 item \#5) connected to the compressor (Fig.1.c item \#6). This type of pump provided a

182 homogeneous suction for all accelerators tested, regardless of the differences in their

183 viscosity. The flow of accelerators was calculated based on the optimal flow of mortar (5.0

$184 \mathrm{~L} / \mathrm{min}$ ). Once the spraying process ended, the remaining unsprayed mortar was poured in

185 metallic moulds placed horizontally over the ground to produce the reference cast specimens

186 (without spraying and accelerator). 


\section{Specimen preparation.}

190 All panels remained in the moulds for $24 \mathrm{~h}$, when they were demoulded and placed in a humid

191.4. chamber $\left(20^{\circ} \mathrm{C}\right.$ and $99 \%$ relative humidity) for $24 \mathrm{~h}$ more. Once the mortar reached enough 192 strength (48 $\mathrm{h}$ after production), prismatic and cylindric specimens were extracted and prepared 193 for the tests. Prismatic specimens were saw cut to the dimension $25 \times 25 \times 250 \mathrm{~mm}$ based on the 194 ASTM C490 [24] for assessing the dimensional variation in mortar specimens. Cylindric 195 specimens were drilled using core bits with approximately $25 \mathrm{~mm}$ diameter and cut to a length 196 of $25 \mathrm{~mm}$ following the methodology in [23] to ensure the slenderness ratio of 2 [23]. Regions 197 at the inclined edges of the panel and near the mould and outer surfaces were discarded as they 198 are prone to lamination.

199

200 Specimens that did not present regularity $( \pm 1 \mathrm{~mm})$, parallelism and proper dimensions $( \pm 1 \%)$

201 after the cutting process were discarded. When this analuysis was finished and specimens

202 were selected, they were cleaned with compressed air and water to avoid the presence of

203 dust. As ESA is a diffusion process, this was carried out to avoid the saturation of the external

204 pores of the specimens and the cores.

$205^{2.5 .}$

Exposure conditions

208 After the extraction, specimens were submerged in water at $20^{\circ} \mathrm{C}$ until the start of sulphate 209 exposure at 7 or 28 days since production, when they were submerged in a sodium sulphate 210 solution with a concentration of $30 \mathrm{~g} / \mathrm{L}$ and $20^{\circ} \mathrm{C}$. For comparison, reference samples of each

211 composition were submerged in water. The earliest exposure time (7 days) was defined to

212 allow enough time for the preparation of specimens, initial inspection and homogenisation of 213 their saturation degree. The $\mathrm{pH}$ of the solutions was measured every 7 days for the first three 
214 months and once a month afterwards. The solutions with sulphates were renewed every

215 month or if the $\mathrm{pH}$ was above 11.

\section{Test Methods}

219 Table 5 shows the tests performed with cylindrical and prismatic specimens, which include 2.6.

220 techniques for assessing the macro and microstructural characteristics during the ESA. The

221 start of the exposure to sulphates was considered time 0 for the accelerated ESA tests and the 222 analysis of the results.

224 An adaptation of the ASTM C490 [24] was used to evaluate the dimensional variation of 225 prismatic specimens. A Digital Demec strain gage measured the change in the distance 226 between 2 stainless steel pins glued $150 \mathrm{~mm}$ apart along the biggest size of the specimen. The 227 measurements were taken weekly during the first month and every other week until the end of 228 the test at 400 days. Before assessing the dimensional variation, specimens were subjected to 229 a visual inspection - to identify cracking, change of colour and spalling - and ultrasound wave 230 velocity test - to indirectly evaluate the matrix deterioration. The equipment Pundit PL-2000

231 with transducers operating at a frequency of $0.5 \mathrm{MHz}$ in direct transmission was used to 232 measure the ultrasound wave velocity (UWV). The transducers were always placed at the 233 exact half of the specimen to minimise the variability of the results.

235 Table 5. Tests performed with cylindrical and prismatic specimens.

\begin{tabular}{|c|c|c|c|c|c|}
\hline \multirow[b]{2}{*}{ Test } & \multirow[b]{2}{*}{ Specimen } & \multicolumn{2}{|c|}{ Number of replicas } & \multirow{2}{*}{$\begin{array}{l}\text { Time } \\
\text { (days) }\end{array}$} & \multirow[b]{2}{*}{ Reference } \\
\hline & & $\begin{array}{l}\text { Sulphate } \\
\text { solution }\end{array}$ & In Water & & \\
\hline Porosity & Cylindrical & & 3 & $\begin{array}{l}\text { Prior to } \\
\text { sulphate } \\
\text { exposure }\end{array}$ & [25] \\
\hline $\begin{array}{c}\text { Dimensional } \\
\text { Variation } \\
\end{array}$ & \multirow{2}{*}{ Prismatic } & 6 & 3 & 0 to 400 & [24] \\
\hline $\begin{array}{c}\text { Visual } \\
\text { inspection }\end{array}$ & & 6 & 3 & 0 to 400 & - \\
\hline
\end{tabular}




\begin{tabular}{|c|c|c|c|c|c|}
\hline $\begin{array}{l}\text { Ultrasound } \\
\text { Wave } \\
\text { Velocity }\end{array}$ & & 6 & 3 & 0 to 400 & [22] \\
\hline $\begin{array}{l}\text { Compressive } \\
\text { Strength }\end{array}$ & Cylindrical & 3 & 3 & 90 & {$[26]$} \\
\hline XRD & \multirow{2}{*}{ Prismatic } & 1 per age & - & $\begin{array}{c}20, \\
40,150,300\end{array}$ & {$[3,27]$} \\
\hline SEM & & 1 per age & - & 400 & [28] \\
\hline
\end{tabular}

237 To assess the evolution of phase composition over time, X-Ray powder diffraction (XRD)

238 was performed in samples extracted from the prismatic specimens exposed to the sulphate

239 solution. A 2 mm-wide slice was cut from the prismatic specimen at 20, 40, 150 and 300

240 days. These were crushed and ground to a maximum particle size of $63 \mu \mathrm{m}$. The powder

241 obtained was analysed by XRD in a PANalytical X'Pert PRO MPD Alpha1 powder

242 diffractometer in Bragg-Brentano $\theta / 2 \theta$, using $\operatorname{CuK} \alpha 1(\lambda=1.5406 \AA)$ radiation at $45 \mathrm{KV}$ and

$24340 \mathrm{~mA}$. The powder diagrams were analysed quantitatively by Rietveld refinement using the

244 software X'Pert High Score Plus and the structure models in Table 6. To quantify the

245 amorphous content of the samples, Rutile (99\% pure) was added at $20 \%$ by sample weight as

246 an internal standard.

248 Scanning electron microscopy (SEM) was used to analyse the microstructure of samples from

249 the middle region of the prismatic specimen at the end of the attack. These were frozen in

250 liquid nitrogen, vacuum dried during $24 \mathrm{~h}$ and coated with carbon. The morphology of phases

251 was analysed in the fracture surfaces, and their chemical composition was assessed by energy

252 dispersive X-ray analysis.

254 Table 6. Phase structures used in the Rietveld analysis.

\begin{tabular}{cccccc}
\hline Phase & Formula & Crystal System & PDF Codes & ICSD & Ref \\
\hline Alite & $\mathrm{Ca}_{3} \mathrm{SiO}_{5}$ & Monoclinic & $01-070-8632$ & 94742 & {$[29]$} \\
\hline Calcium Aluminate & $\mathrm{Ca}_{3} \mathrm{Al}_{2} \mathrm{O}_{6}$ & Cubic & $00-038-1429$ & 1841 & {$[30]$} \\
\hline Ferrite & $\mathrm{Ca}_{2} \mathrm{AlFeO}_{5}$ & Orthorhombic & $01-071-0667$ & 9197 & {$[31]$} \\
\hline Gypsum & $\mathrm{CaSO}_{4}-2 \mathrm{H}_{2} \mathrm{O}$ & Monoclinic & $00-033-0311$ & 151692 & {$[32]$} \\
\hline Calcite & $\mathrm{CaCO}_{3}$ & Rhombohedra & $01-083-0577$ & 79673 & {$[33]$} \\
\hline Portlandite & $\mathrm{Ca}(\mathrm{OH})_{2}$ & Rhombohedra & $01-072-0156$ & 15741 & {$[34]$} \\
\hline Ettringite & $\mathrm{Ca}_{6} \mathrm{Al}_{2}\left(\mathrm{SO}_{4}\right)_{3} \cdot(\mathrm{OH})_{12} \cdot 26 \mathrm{H}_{2} \mathrm{O}$ & Hexagonal & $00-041-1451$ & 155395 & {$[35]$} \\
\hline Monosulfoaluminate & $\mathrm{Al}_{2}(\mathrm{OH})_{12} \cdot \mathrm{SO}_{4} \cdot 6 \mathrm{H}_{2} \mathrm{O}$ & Rhombohedra & -- & 24461 & {$[36]$} \\
\hline
\end{tabular}




\begin{tabular}{ccccccc}
\hline Hemicarboaluminate & $\mathrm{Ca}_{4} \mathrm{Al}_{2}(\mathrm{OH})_{12} \cdot \mathrm{OH} \cdot 0.5 \mathrm{CO}_{3} \cdot 4 \mathrm{H}_{2} \mathrm{O}$ & Rhombohedra & $00-041-0221$ & 263124 & {$[37]$} \\
\hline Monocarboaluminate & $\mathrm{Ca}_{4} \mathrm{Al}_{2}(\mathrm{OH})_{12} \cdot\left(\mathrm{CO}_{3}\right) \cdot 5 \mathrm{H}_{2} \mathrm{O}$ & Triclinic & $01-087-0493$ & 59327 & {$[38]$} \\
\hline Thenardite & $\mathrm{Na}_{2} \mathrm{SO}_{4}$ & Orthorhombic & $01-070-1541$ & 2895 & {$[39]$} \\
\hline Dolomite & $\mathrm{CaMg}\left(\mathrm{CO}_{3}\right)_{2}$ & Rhombohedra & $01-075-1761$ & 31335 & {$[40]$} \\
\hline Quartz & $\mathrm{SiO}_{2}$ & Hexagonal & $01-083-2465$ & 200721 & {$[41]$} \\
\hline Rutile & $\mathrm{TiO}_{2}$ & Tetragonal & $01-089-4202$ & 44881 & {$[42]$} \\
\hline
\end{tabular}

$256 \quad 3 . \quad$ Results and discussion.

\section{Porosity characterization before sulphate exposure}

260 3.1. Figure 2 depicts the results of water accessible porosity for all sprayed and poured mixes

261 before immersion in the sulphate solution at 7 or 28 days since production. As expected, a

262 reduction in porosity is observed from 7 to 28 days. Such variation is mainly attributed to the

263 hydration of phases in the cement since the exposition to sulphates had not started yet.

Figure 2. Water accessible porosity.

On average, the porosity reduction in the reference compositions (not sprayed and without accelerators) is 2.7 times higher than in sprayed compositions with accelerators. This result

269 confirms findings of previous studies $[2,43]$ and indicates that the incorporation of

270 accelerators compromises the proper consolidation of the sprayed material and the elimination

271 of entrapped air due to the fast setting of the matrix. As described by [44], this may also be

272 explained by the inhibition of alite hydration in accelerated mortars, which limits the amounts

273 of hydration products formed and the filling of pores.

275 The results obtained are similar to previous publications [2,43]. They suggest that sprayed

276 mixtures have the highest values of porosity at both ages due the incorporation of

277 accelerators, which reduce the setting time of the matrix. Therefore, the matrix does not

278 consolidate properly and does not eliminate the entrapped air, increasing its porosity. The 
results are directly proportional to the ettringite formation calculated in Table 4, the

280 exceptions are the mixtures with the AR080 accelerator.

Comparing the porosity of CI_AR080_3\% (16.24\%) and CI_AR130_3\% (14.22\%), the mixtures that incorporates AR080 presents the lowest ettringite formation and the lowest $\mathrm{Al}_{2} \mathrm{O}_{3} / \mathrm{Na}_{2} \mathrm{O}$ ratio. One possible explanation is the incorporation of elevated concentrations of sodium, this may lead to a porous matrix $[45,46]$ due to the variation in the composition and compactness of the C-S-H chains and the AFm phases. mixtures is $5.9 \%$, in the sprayed mixtures this value is $2.2 \%$. As alite hydration is inhibited in accelerated mortars [44], lower amounts of hydration products are formed. Because of that, the filling of pores occurs less intensively, leading to lower reductions in porosity.

Figure 3.a and 3.b show the dimensional variation over time for the specimens with CEM I and CEM II, respectively. The values presented in the graphs are the difference between the average dimensional variation for the composition submerged in the sodium sulphate solution and the average dimensional variation for the same composition submerged in water. This procedure intends to isolate the expansion attributed to the ESA from the expansion that could happen as a result of the hydration of phases in a submerged condition.

Figure 3. Dimensional variation in sprayed mortars with (a) CEM I and (b) CEM II.

304 The reference cast specimens (CI_REF_28 and CII_REF_28) present negligible dimensional

305 variation caused by sulphate penetration over 400 days of ESA. Such results may be

306 attributed to the low aluminate content of these cement that are considered SR [20] and to the 
307 lower porosity of the mixes extracted from cast panels without accelerator. By contrast, the

308 specimens of sprayed mortars with accelerator show expansions ranging from 0.5 to $7 \mathrm{~mm} / \mathrm{m}$

309 at 400 days. This may be the result of the higher porosity induced by the spraying process,

310 which could favour sulphate ingress and the additional aluminate content provided by the

311 accelerators that could contribute to the formation of expansive phases.

313 The mixes with AR accelerators show more significant expansion than the mixes produced

314 with AF accelerators. Notice that specimens sprayed with AR accelerators present the highest

315 porosity (Figure 2) amongst all analysed here. The significant expansion of the mix with

316 AR080 accelerator is enough to produce an early failure of the specimens and the interruption

317 of the test. Specimens with AR080 accelerator using CEM I and CEM II exposed to sulphates

318 at 28 days since production failed approximately 120 days after the beginning of accelerated

319 ESA. Specimens with AR accelerator and CEM II exposed to sulphates at 7 days since

320 production withstood even less time in the accelerated ESA, failing only 30 days from the

321 beginning of the test. This suggests that the spraying process with accelerates leads to a

322 significant reduction in the expected durability in comparison with reference cast specimens

323 without accelerators. Such reduction is observed despite using SR cement and is particularly

324 evident in mixes with AR accelerators.

326 Specimens exposed to sulphates at 7 days since production presented up to 5-times higher

327 expansion than equivalent specimens exposed to sulphates at 28 days since production. These

328 differences appear faster in mixes with AR accelerator than in mixes with AF accelerator.

329 Both outcomes may be related to the more rapid sulphate ingress induced by the larger

330 interconnected porosity at 7 days in comparison with 28 days and in mixes with AR

331 accelerator in comparison with those with AF accelerators.

333 Skalny et al. [47] suggest an expansion of $0.1 \%$ as a safe margin for determining the

334 maximum expansion without significant degradation in mixes under sulphate attack. 
335 Crammond [48] recommends that the $0.1 \%$ expansion should not be exceeded after 6 months

336 of testing. Although the experimental procedure adopted may affect the results, only cast

337 specimens without accelerators fulfil this requirement, which is consistent with the use of SR

338 cement. Conversely and despite using the same cement, 5 of the mixes sprayed with

339 accelerator show expansions between 2.1 and 8.7 times higher than the limit while the

340 remaining 3 had already failed much before reaching 6 months of testing.

\section{Visual Inspection}

344 Figure 4 shows images from the visual inspection of specimens at the beginning of the ESA

345 and at the latest time during the test (400 days for those not failing and less for those failing

346 before the end of the test). All cast specimens experience a slight change in their surface

347 colour during the 400 days of sulphate exposure, which may be related to the precipitation of

348 phases (see example in Figures 4.a and 4.b for CI_REF_28 and CII_REF_28, respectively).

349 By contrast, in addition to the change in colour, almost all sprayed specimens with accelerator

350 present cracking, as shown in Figures 4.c to 4.j. This confirms that the spraying process with

351 accelerators might reduce the durability in elements exposed to ESA.

Figure 4. Visual inspection of the cast and sprayed specimens before and after the

354 accelerated ESA.

356 The mixes with the accelerator AR080 present the highest degrees of degradation (Fig 4.f, Fig

357 4.i and Fig 4.j), with longitudinal and transversal cracking near the edges and in the central

358 part of the specimens. These results are consistent with the higher expansion measured in

359 sprayed mixes with AR accelerator.

361 Edge cracking is usually the first visual consequence of the ESA, associated with an

362 intensification of sulphate penetration combined with low material confinement in those 
regions. Longitudinal and cracking of the cross section are serious failure modes caused by

364 the interaction between the sound core of the specimen and the external layers directly

365 affected by sulphate penetration. Figure 4 shows that failure in the cross-section happens

366 more often than longitudinal cracking or spalling, which agrees with the findings by $[49,50]$.

367 These authors stated that the tensile stress generated in the core of specimens with small

368 cross-section due to the expansion of the external layers (related to cross-sectional failure) are

369 more critical than the stress generated in the interface between the damaged and sound

370 regions (related to spalling).

372 Specimens exposed to sulphates at 7 days show earlier formation of cracks and higher degrees

373 of damage than specimens exposed to sulphates at 28 days. The comparison of specimens

374 with different cement types (Figure 4.a and 4.b or Figure 4.f and 4.i) does not reveal any

375 significant difference, thus suggesting a similar behaviour.

377.4. Ultrasound wave velocity (UWV).

379 Figure 5 presents the evolution of the UWV over time for mixes subjected to ESA. Variations

380 in the UWV are caused by changes in the density, elastic modulus and integrity of the

381 specimens. All curves in Figure 5 show a similar trend characterised by two stages: an

382 increase of the UWV up to a maximum (Stage 1) followed by a reduction of UWV until the

383 end of the test or failure of the specimen (Stage 2).

385 Stage 1 comprises the early ages of the attack when the phases produced by cement hydration 386 and the ESA contribute to reduce the porosity and the ESA contribute to reduce the porosity 387 and increase the mechanical properties of the mixture cause by the space filling. This effect 388 caused by the precipitation prevails. In Stage 2 - comprehending from maximum UWV 389 onwards - the deposition of expansive phases causes significant micro-cracking that acts like 
obstacles to the wave propagation. This effect prevails over the potential increase arising from

391 the densification of the matrix.

Figure 5. UWV in mixes subjected to ESA.

Table 7 summarises the initial UWV at the start of the exposure to ESA $\left(\mathrm{UWV}_{0}\right)$, the

396 variation observed during the test $\left(\mathrm{UWV}_{\mathrm{end}}-\mathrm{UWV}_{0}\right)$, the maximum velocity $\left(U W V_{\max }\right)$ and

397 the time it occurs $\left(t_{\max }\right)$, and the maximum variation $\left(U W V_{\text {end }}-U W V_{\max }\right)$. Notice that $U W V_{\text {end }}$

398 refers to the last measurement taken (at 400 days for specimens not failing and at time of

399 failure for others).

400

401 From time 0 to the end of the test, cast mixes experience a UWV increase consistent with

402 limited micro-structural damage due to the ESA. Conversely, sprayed mixes with accelerators

403 present mainly negative UWV variations, which indicate significant micro-structural

404 deterioration.

405

Table 7. Parameters obtained from the UWV curves in Figure 5.

\begin{tabular}{cccccc}
\hline $\begin{array}{c}\text { Mortar } \\
\text { Sample }\end{array}$ & $\begin{array}{c}\mathrm{UWV} \\
(\mathrm{m} / \mathrm{s})\end{array}$ & $\begin{array}{c}\mathrm{UWV} \text { max } \\
(\mathrm{m} / \mathrm{s})\end{array}$ & $\begin{array}{c}\mathrm{t}_{\max } \\
(\mathrm{days})\end{array}$ & $\begin{array}{c}\mathrm{UWV} \text { end } \\
\mathrm{UWV} \text { max } \\
(\mathrm{m} / \mathrm{s})\end{array}$ & $\begin{array}{c}\mathrm{UWV}_{\text {end }} \\
\mathrm{UWV}_{0} \\
(\mathrm{~m} / \mathrm{s})\end{array}$ \\
\hline CI_REF_28 & 4055.6 & 4158.9 & 126 & -46.1 & 57.2 \\
\hline CI_AF060_5\%_7 & 3881.9 & 4115.1 & 56 & -230.2 & 3.0 \\
\hline CI_AF060_5\%_28 & 3938.5 & 4107.1 & 56 & -146.0 & 22.6 \\
\hline CI_AF040_5\%_28 & 3946.9 & 4104.7 & 21 & -163.5 & -5.7 \\
\hline CI_AR130_3\%_7 & 3826.3 & 4007.4 & 42 & -474.8 & -293.8 \\
\hline CI_AR130_3\%_28 & 3872.8 & 4107.8 & 28 & -454.2 & -219.2 \\
\hline CI_AR080_3\%_28 & 3697.0 & 3887.8 & 28 & -438.7 & -247.9 \\
\hline CII_REF_28 & 3980.5 & 4062.7 & 126 & -50.8 & 31.4 \\
\hline CII_AR080_3\%_7 & 3318.6 & 3471.4 & 21 & -797.2 & -644.4 \\
\hline CII_AR080_3\%_28 & 3651.5 & 3753.7 & 21 & -338.8 & -236.6 \\
\hline
\end{tabular}

$408 \mathrm{UWV}_{\max }$ occurs 2.3 to 6.0 times earlier in sprayed mixes with accelerator than in cast mixes

409 without accelerator. This reveals a quicker onset of the damage, possibly due to a more rapid 
sulphate ingress promoted by the higher porosity and the capacity to form expansive phases in

411 sprayed mixes with accelerators. After reaching $\mathrm{UWV}_{\max }$, cast mixes experience a UWV

412 reduction 14 times smaller than that observed in sprayed mixes with accelerators, which

413 confirms the more intense damage of the latter due to the ESA.

415 The level of degradation assessed for mixes with AR accelerators is on average 2.5 times 416 higher than that of mixes with AF accelerators. Such results are consistent with the visual 417 inspection and the dimensional variation in Figure 3. Mixes with $\mathrm{Al}_{2} \mathrm{O}_{3} / \mathrm{Na}_{2} \mathrm{O}$ ratio of 0.8 418 (AR080) present a higher deterioration in a shorter period than the mixes with $\mathrm{Al}_{2} \mathrm{O}_{3} / \mathrm{Na}_{2} \mathrm{O}$ 419 ratio of 1.3 (AR130). This suggests that a lower $\mathrm{Al}_{2} \mathrm{O}_{3} / \mathrm{Na}_{2} \mathrm{O}$ ratio may affect negatively the 420 durability of accelerated matrices exposed to sulphates. The higher proportion of sodium in 421 relation to aluminates could contribute to the formation of AFm with higher solubility that 422 would react and form ettringite more quickly.

\subsection{Compressive strength}

426 Table 8 shows the average compressive strength $(\bar{X})$ at 98 days for the mixes with CEM I and 427 the relative reduction between the mixes exposed to sulphate and equivalent ones in water. 428 All compositions exposed to sulphates show a strength reduction due to the progressive 429 micro-cracking associated with the ESA. The mix CI_REF_28 presents the smallest relative 430 reduction, which reflects the limited damage expected in cast mixes with SR cement.

432 Relative reductions are marginally higher in sprayed mixes with AF accelerators for the first 43398 days of exposition to sulphates, which suggests that the additional damage observed in the 434 UWV and dimensional variation caused by the ESA does not significantly compromise the 435 compressive strength. Conversely, sprayed mixes with AR accelerator showed relative differences 6.6 to 9.6 times higher than those of cast specimens and overall compressive 
438 significantly the compressive strength during the first 98 days of the accelerated ESA.

Table 8. Compressive strength for mortars with CEM I.

\begin{tabular}{cccccc}
\hline \multirow{2}{*}{ Mix } & \multicolumn{2}{c}{ In water } & \multicolumn{2}{c}{$\begin{array}{c}\mathrm{In} \mathrm{Na}_{2} \mathrm{SO}_{4} \\
\text { solution }\end{array}$} & $\begin{array}{c}\text { Relative } \\
\text { reduction }\end{array}$ \\
\hline & $\bar{X}$ & $\mathrm{CV}$ & $\bar{X}$ & $\mathrm{CV}$ & \\
& $(\mathrm{MPa})$ & $(\%)$ & $(\mathrm{MPa})$ & $(\%)$ & $(\%)$ \\
\hline CI_REF_28 & 38.66 & 5.48 & 36.80 & 11.38 & 4.83 \\
\hline CI_AF060_5\%_7 & 31.48 & 26.04 & 29.15 & 21.04 & 7.38 \\
\hline CI_AF060_5\%_28 & 33.32 & 19.78 & 31.19 & 24.07 & 6.40 \\
\hline CI_AR130_3\%_7 & 31.57 & 12.96 & 16.98 & 23.06 & 46.24 \\
\hline CI_AR130_3\%_28 & 34.70 & 23.93 & 23.69 & 19.74 & 31.72 \\
\hline
\end{tabular}

442 Sprayed mixes with AF and AR accelerators exposed at 7 days since production present

443 respectively $13.3 \%$ and $31.4 \%$ higher relative strength reduction in comparison to

444 corresponding ones exposed at 28 days since production. In other words, the sprayed mix

445 with AR accelerator is 2.2 times more sensitive to the age of exposition than equivalent

446 sprayed mix with AF accelerator. The trends observed here are consistent with those

447 identified in previous tests.

448

3.6.

\section{X-ray diffraction}

Figure 6 shows the mass percentage of ettringite (6.a) and gypsum (6.b) formed during the exposition to sulphates. The quantification of AFm was deemed not accurate enough due to the low intensity of the AFm peaks compared to the intensity of calcite peaks from the

454 aggregate ( $>60 \%$ of the composition by weight). Assessment for mixes whose specimens

455 failed before the end of the test were only conducted until the damage led to a free sulphate 456 ingress in the matrix, thus potentially compromising the quantification. The missing results 457 for later times are represented in red with the same magnitude as the last valid quantification. 
The amount of ettringite in mixes without accelerator (CI_REF_28 and CII_REF_28) is

460 significantly smaller than in the rest of sprayed mixes throughout the accelerated test. Since

461 accelerators provide an extra source of aluminium to the mortar, a larger amount of AFm

462 phase is expected as hydration progresses [3,21]. Therefore, more ettringite should be

463 quantified in accelerated matrices as AFm phases react with the sulphate ions from the

464 solution, forming secondary ettringite. The secondary ettringite formed is the main

465 responsible for the expansion in Figure 3 and the degradation found in visual inspections,

466 UWV and compressive strength.

467

Figure 6. Phases formed in the mixes: (a) Ettringite and (b) Gypsum.

470 The amount of gypsum (Fig 6.b) is lower than $1 \%$ in all mixes except for the ones with

471 AR080 accelerator. The formation of gypsum can be a preliminary stage to the formation of

472 ettringite. However, as mentioned by [20], it is still unknown if the gypsum intervenes in the 473 expansions and deterioration caused by the ESA.

The formation of secondary ettringite is also influenced by the accelerator type. Mortars containing AR accelerators (CI_AR130_3\%_28 and CI_AR080_3\%_28) present larger amounts of ettringite compared to the equivalent mortars produced with AF accelerators (CI_AF060_5\%_28 and CI_AF040_5\%_28) at 300 days of ESA. Since the AR accelerators has a higher $\mathrm{C}_{3} \mathrm{~A} / \mathrm{SO}_{3}$ ratio, larger amounts of $\mathrm{AFm}$ phases are formed, leading to a higher quantity of secondary ettringite during the ESA. 
belongs to the group of hexagonal or pseudo-hexagonal layered structures like the AFm, where sodium is present between the layers increasing the interlayer distance of the crystals

491 The cast mixes with CEM I present higher content of ettringite than equivalent mixes with

CEM II. This is consistent with the higher $\mathrm{C}_{3} \mathrm{~A}$ content in the CEM I $(4.7 \% \mathrm{bcw})$ in

493 comparison with CEM II (3.6\% bcw), which should be proportional to the potential to form

494 ettringite. The same trend is not as clear in sprayed mixes due to the interaction with

495 compounds provided by the accelerators and the early damage experienced by specimens.

497 Results at 300 days reveal that mixes exposed to sulphates at 7 days since production have 498 approximately 1.33 times more ettringite than equivalent mixes exposed to sulphates at 28 499 days since production. The larger ettringite content is also related to the higher connected 500 porosity of mixes exposed at earlier ages, which favours the sulphate ingress and the 501 consequent formation of ettringite. As hydration progresses, the porosity is reduced, limiting 502 the diffusion of sulphates in the matrix. The influence of this variable is particularly evident 503 in mixes with AR080 accelerator whose specimens exposed at 7 days since production have 504 twice as much ettringite as specimens exposed at 28 days. This is possibly one of the reasons 505 for the earlier failure of specimens exposed to sulphates at 7 days in comparison with those 506 3.7. exposed at 28 days since production.

\section{Scanning Electron Microscopy}

510 Mortar compositions CI_REF_28, CI_AF060_3\%_28, CI_AR130_3\%_28 and

511 CI_AR080_3\%_28 exposed to sulphates were evaluated through SEM at 400 days. Figure 7 512 shows the results for the cast mix CI_REF_28 without accelerator. The regions analysed by 513 EDS are indicated by a white circle in the image. Results obtained in the EDS spectra are 
514 represented as the relative intensities of each element, placed above each image. These intensities are important to identify the relative relation between each other and correlate with

516 the chemical composition of the phases analyzed. The peaks considered to measure the intensity

517 of $\mathrm{Ca}, \mathrm{Si}, \mathrm{S}$ and $\mathrm{Al}$ correspond to the energies of $3.73,1.78,2.33$ and $1.52 \mathrm{keV}$, respectively.

518 The intensity-base ratios are important to identify the presence of the hydrated aluminium 519 phases. According to [21,44], a 0.33 ratio indicates the presence of ettringite. Ratios below 0.33 520 indicate the presence of ettringite and sulfates. Normally, the ultimate phase of the alumiunium 521 hydration is monosulfoaluminate $(\mathrm{Al} / \mathrm{S}=0.66)$ and $\mathrm{C}-\mathrm{A}-\mathrm{H}$ hydrates $(\mathrm{Al} / \mathrm{S} \geq 0.66) . \mathrm{Al} / \mathrm{S}$ ratio 522 values between 0.33 and 0.66 indicate the possible presence of a secondary product like 523 ettringite in the pores $[3,21,44]$.

524

Figure 7. SEM images and EDS analysis of pore (a) and detail of ettringite formation (b) in

528 Figure 7.a shows a pore filled with plate-like crystals. The $\mathrm{Al} / \mathrm{Ca}, \mathrm{Si} / \mathrm{Ca}$, and $\mathrm{Al} / \mathrm{S}$ intensity529 base ratios are respectively equal to $0.24,0.16$ and 0.72 , indicating a potential presence of C-

$530 \mathrm{~S}-\mathrm{H}, \mathrm{AFt}$ and AFm phases. Further approximation inside the pore reveals needle-like crystals 531 measuring $10 \mu \mathrm{m}$ in length characterised by an $\mathrm{Al} / \mathrm{S}$ intensity-base ratio of 0.63 , indicating the 532 presence of ettringite (see Figure 7.b). Ettringite in this case seems to appear with the AFm 533 phase $(\mathrm{Al} / \mathrm{S} \geq 0.66)$ indicating that secondary ettringite is barely formed due to the low $\mathrm{C}_{3} \mathrm{~A}$ 534 content in the cement. Normally, it is expected to find ettringite in earlier stages of hydration.

535 However, these samples are 400 days old. The presence of AFm is expected in higher ratios 536 as is the normal hydration of aluminates in cement. The results are in line with the low 537 ettringite formation detected in XRD analyses of the mix (see Figure 6). Sodium was not 538 identified in the EDS of the sample. 
540 Figure 8 shows the SEM images and the EDS of the sprayed mix CI_AF060_5\%_28. The

541 EDS spectrum In Figure 8.a shows $\mathrm{Al} / \mathrm{Ca}, \mathrm{Si} / \mathrm{Ca}$ and $\mathrm{Al} / \mathrm{S}$ intensity-base ratios respective

542 equal to $0.11,0.19$ and 1.1, indicating presence of C-S-H and AFm phases. The main

543 sulfoaluminate phase found was AFm, which can be related to the introduction of sulphates

544 ions by the accelerator.

546 Figure 8. SEM image and EDS analysis of the matrix (a) and ettringite formation (b) in

547 CI_AF060_5\%_28

549 Figure 8.b shows a pore filled with $20 \mu \mathrm{m}$-long needle-like formation with an Al/S intensity-

550 base ratio of 0.30 , indicating a combination of AFt phase and sulphates. This is consistent

551 with the XRD results that show increasing contents of ettringite in mixes with AF accelerator

552 in comparison with those without accelerator. Once more, sodium was not found in the matrix

553 or the pores.

555 Figure 9 shows SEM images and the EDS analysis of the mix CI_AR130_3\%_28. Figure 9.a

556 reveal $\mathrm{Al} / \mathrm{Ca}, \mathrm{Si} / \mathrm{Ca}$ and $\mathrm{Al} / \mathrm{S}$ intensity-base ratios that suggest the presence of ettringite and

557 C-S-H. In this case, sodium is found in EDS results of the sample. The sodium could come

558 from the alkaline accelerator and the $\mathrm{Na}_{2} \mathrm{SO}_{4}$ diluted in water. Since the sodium was only

559 found in the mixes with the AR accelerator, the most likely source is deemed the accelerator

560 that incorporates $\mathrm{Na}^{+}$and $\mathrm{Al}\left[(\mathrm{OH})_{4}\right]^{-}$ions into the matrix during hydration [3]. Depending on

561 the $\mathrm{Na}^{+}$concentration, phases with sodium, calcium and aluminate may be formed.

563 Figure 9. SEM image and EDS analysis of the matrix (a) and ettringite (b) in

564 CI_AR130_3\%_28

566 The presence of sodium may lead to a more porous matrix $[45,46]$ due to variation in the

567 composition of C-S-H and AFm phases. In Figure 9.a, sodium is found in the C-S-H 
composition, which changes to a system with lower density due to the lower $\mathrm{Ca}-\mathrm{Si} /(\mathrm{Si}+\mathrm{Al})$ ratio compared to alkali-free systems $[45,46]$. AFm phases were not found in Figure 9, probably due to the enhanced solubility of these phases in the presence of sodium. Figure 9.b

571 shows the inside of a pore characterised by an $\mathrm{Al} / \mathrm{S}$ ratio equal to 0.46 that is consistent with 572 ettringite in the presence of sulphates.

574 Figure 10 shows the SEM images and the EDS of the mix CI_AR080_3\%_28. According to 575 the EDS results in Fig 10.a, $\mathrm{Al} / \mathrm{Ca}, \mathrm{Si} / \mathrm{Ca}$, and $\mathrm{Al} / \mathrm{S}$ intensity-base ratios respectively of 0.07 , $576 \quad 0.15$ and 0.38 indicate a possible presence of C-S-H and AFt phases. Sodium is also found 577 with a $\mathrm{Na} / \mathrm{Ca}$ intensity-base ratio equal to 0.23 , which is higher than in the mix with AR130 578 (0.07). Sodium seems to remain in the C-S-H, which explains the higher porosity found in the 579 mixes with accelerator AR080. Figure 10.b shows the formation of $40 \mu \mathrm{m}$-long needle-shaped 580 crystals with $\mathrm{Al} / \mathrm{S}$ intensity-base ratio equal to 0.22 , indicating a typical ettringite formation 581 with a high content of sulphates. These are the longest and more abundant ettringite needles

582 found across all specimens analysed, thus justifying the XRD results and the damage 583 observed in sprayed mixes with AR080. formation in CI_AR080_3\%_28.

\section{Influence of theoretical $\mathrm{C}_{3} \mathrm{~A} / \mathrm{SO}_{3}$ of the mix with accelerator}

Figure 11 shows the relationship between the theoretical $\mathrm{C}_{3} \mathrm{~A} / \mathrm{SO}_{3}$ of the mix with accelerator

591 summarised in Table 4 (x-axis of all graphs) and the main results obtained in the experimental programme (y-axis). Only results of mixes exposed to sulphates 28 days since production are

593 depicted in Figure 11 to ensure the comparison under nearly identical conditions. The 594 reduction of compressive strength and porosity were assessed at 90 days of sulphate exposure 
and just before sulphate exposure, respectively. Other results correspond to approximately

596300 days of accelerated ESA.

Figure 11. Relationship between the theoretical $\mathrm{C}_{3} \mathrm{~A} / \mathrm{SO}_{3}$ of the mix with accelerator and the ettringite formation, maximum ultrasound variation, linear expansion, strength reduction and porosity

601

602 A similar linear trend is observed for the ettringite formation, the maximum ultrasound 603 variation, the linear expansion and the reduction of compressive strength (notice that results

604 for only 3 mixes are available for the latter). This confirms that the increase of the theoretical $605 \mathrm{C}_{3} \mathrm{~A} / \mathrm{SO}_{3}$ of the mix with the accelerator is related to the potential ettringite formation and the consequent magnitude of micro- and macro-structural changes induced by the ESA. A less

607 clear trend was observed with the porosity, which is influenced by other aspects related to the 608 production process that might have eclipsed the effect of the $\mathrm{C}_{3} \mathrm{~A} / \mathrm{SO}_{3}$.

\section{Conclusions}

611

612 The following conclusions are derived from the study conducted here.

614 Sprayed mixes with accelerator showed more ettringite, larger ettringite crystals and

615 several times larger linear expansion than equivalent cast mixes without accelerator. This led 616 to more damage at the micro- and macro-structural levels observed in the ultrasound results,

617 visual inspection and mechanical tests results. The spraying process increases the

618 interconnected porosity and favours the sulphate ingress. The inclusion of set accelerators

619 provides an additional amount of aluminate phases that may react with sulphates in the ESA

620 and contribute to the development of expansion and damages. Both factors seem the main

621 responsible for the higher vulnerability to the ESA of sprayed mixes with accelerator in

622 comparison with equivalent cast mixes without accelerator. A direct relationship was found 
623 between the theoretical $\mathrm{C}_{3} \mathrm{~A} / \mathrm{SO}_{3}$ of the mix with accelerator and the expansion- and damage-

624 related parameters assessed during the ESA.

625

Alkaline accelerators triggered higher ettringite formation, expansion and

deterioration than alkali-free accelerators. The absence of sulphates in alkaline accelerators

631 due to the low capacity of the gel to accomodate the expansions

634 durability of sprayed specimens to the ESA. Specimens exposed at 7 days since production had significantly higher deterioration and expansion than those exposed at 28 days since production. As most sprayed structures are exposed to sulphates immediately after spraying, the accelerated ESA on specimens should be performed at earlier ages to obtain more realistic 638 predictions for such applications.

640 - Despite using SR cement in all mixes, sprayed specimens presented severe and early

641 signs of damage, which was not found in any of the reference cast specimens without

642 accelerator. While both cast mixes without accelerator experienced expansion below the limit

643 considered safe according to the literature [47][48], mixes sprayed with accelerator showed

644 expansions more than 2.1 times the limit or failed even before the 6 months of testing. This

645 reveals that the use of SR cement in sprayed mixes with accelerators is not enough measure to

646 mitigate the consequences of the ESA. 
648 Based on these findings, the following practical recommendations are proposed to reduce the

649 negative consequences of ESA in elements exposed to sulphates and constructed with sprayed 650 mixes with accelerators.

651

652 - The common practice found in guidelines and adopted in projects that rely mainly on 653 the use of SR cement should be revisited. Limitations should be defined for the total content 654 of potentially expansive aluminates (cement+accelerator) per volume of concrete and the $655 \mathrm{C}_{3} \mathrm{~A} / \mathrm{SO}_{3}$.

656

657 In the absence of such recommendations, specific experimental tests should be 658 conducted to assess the impact of spraying with accelerators on the durability of mixes 659 subjected to ESA.

660

661 Alkali-free accelerators should be the preferred choice in applications under risk of 662 ESA. If alkali-rich accelerators must be used, those with lower sodium content should be 663 chosen.

664

\section{Acknowledgements}

666

667 The first author thanks the CONICIT (Consejo Nacional para Investigaciones Científicas y

668 Tecnológicas, process FI-108B-14) of Costa Rica for the scholarship. The second author

669 thanks FAPESP (Fundação de Amparo à Pesquisa do Estado de São Paulo, process

670 2017/00125-9) for the scholarship. This research was possible due to the projects BIA2016-

671 78740-R (MAPPU) and RTC-2015-3185-4 (MAPMIT), co-funded by the Ministerio de

672 Economía y Competitividad of Spain in the Call Retos-Colaboración 2015 and by the

673 European Union through FEDER funds under the objective of promoting the technological

674 development, innovation and high quality research. Special thanks for the technical and 
675 financial support to Industrias Químicas del Ebro, to Centro para el Desarrollo Industrial

676 (CDTi) and to the Ministerio de Economía y Competitividad, all of them in the context of the 677 project IDI-20130248.

678

679 References

680

681 [1] T. Garcia, L. Agulló, A. Aguado, Mix design procedure for shotcrete, Hormigón y Acero, nº 220,

683 [2] I. Galobardes Reyes, Characterization and control of wet-mix sprayed concrete with accelerators 684 (Ph.D Thesis), Polytechnic University of Catalunya, 2013.

685 [3] R.P. Salvador, S.H.. Cavalaro, I. Segura, A.D. Figueiredo, J. Pérez, Early age hydration of 686 cement pastes with alkaline and alkali-free accelerators for sprayed concrete, Constr. Build. Mater. 111 (2016) 386-398. doi:10.1016/j.conbuildmat.2016.02.101.

688 [4] J. Ortiz, A. Aguado, L. Agulló, T. García, Influence of environmental temperatures on the 689 concrete compressive strength: Simulation of hot and cold weather conditions, Cem. Concr. Res.

691 [5] F.R. Steindl, A. Baldermann, I. Galan, M. Sakoparnig, L. Briendl, M. Dietzel, F. Mittermayr,

694 [6] F. Mittermayr, A. Baldermann, C. Kurta, T. Rinder, D. Klammer, A. Leis, J. Tritthart, M. Dietzel, 695 (2013) 55-64. doi:10.1016/j.cemconres.2013.03.003.

697 [7] I. Galan, L. Briendl, M. Thumann, F. Steindl, R. Röck, W. Kusterle, F. Mittermayr, Filler Effect in Shotcrete, Mater. J. (2019). https://doi.org/10.3390/ma12193221.

699 [8] ASTM C150-07, Standard Specification for Portland Cement, Annu. B. ASTM Standars. 552 (2007).

701 [9] AENOR, UNE EN 197-1 2011 Composition, specifications and conformity criteria for common cements., (2009) 9-11.

703 [10] C. Paglia, F. Wombacher, H. Böhni, M. Sommer, An evaluation of the sulfate resistance of cementitious material accelerated with alkali-free and alkaline admixtures: Laboratory vs. field, 
706 [11] C. Paglia, F. Wombacher, H. Böhni, The influence of alkali-free and alkaline shotcrete accelerators within cement systems: Influence of the temperature on the sulfate attack mechanisms and damage, Cem. Concr. Res. 33 (2003) 387-395. doi:10.1016/S00088846(02)00967-5.

[12] B. Rasheeduzzafar, S.N. Abduljauwad, Magnesium-Sodium sulfate attack in plain and blended

[13] O.S. Baghabra Al-Amoudi, Attack on plain and blended cements exposed to aggressive sulfate environments, Cem. Concr. Compos. 24 (2002) 305-316. doi:10.1016/S0958-9465(01)00082-8.

[14] F. Bellmann, B. Möser, J. Stark, Influence of sulfate solution concentration on the formation of

[15] N.N. Naik, A.C. Jupe, S.R. Stock, A.P. Wilkinson, P.L. Lee, K.E. Kurtis, Sulfate attack

[16] T. Schmidt, Sulfate attack and the Role of Internal carbonate on the formation of thaumasite,

[17] Y. Senhadji, M. Mouli, H. Khelafi, A.S. Benosman, Sulfate attack of Algerian cement-based material with crushed limestone filler cured at different temperatures, Turkish J. Eng. Environ.

[18] E.F. Irassar, V.L. Bonavetti, M.A. Trezza, M.A. González, Thaumasite formation in limestone

[19] D. Torréns-Martín, L. Fernández-Carrasco, Effect of sulfate content on cement mixtures, Constr.

[20] A. Neville, The confused world of sulfate attack on concrete, Cem. Concr. Res. 34 (2004) 1275-

[21] C. Herrera-Mesen, R.P. Salvador, S.H.P. Cavalaro, A. Aguado, Effect of gypsum content in sprayed cementitious matrices: Early age hydration and mechanical properties, Cem. Concr. Compos. 95 (2019) 81-91. doi:10.1016/j.cemconcomp.2018.10.015. 
[22] R.P. Salvador, S.H.. Cavalaro, I. Segura, M.G. Hern??ndez, J. Ranz, A.D. de Figueiredo, Relation between ultrasound measurements and phase evolution in accelerated cementitious

[23] AENOR, UNE-EN 14488-1 Ensayos de hormigón proyectado parte 1: toma de muestra de

[24] ASTM, ASTM: C490 Standard Practice for Use of Apparatus for the Determination of Length Change of Hardened Cement Paste, Mortar, and Concrete 1, ASTM Int. (2008) 1-5.

[26] ASTM, ASTM C39 Standard Test Method for Compressive Strength of Cylindrical Concrete

[27] R.P. Salvador, S.H.P. Cavalaro, M. Cano, A.D. Figueiredo, Influence of spraying on the early hydration of accelerated cement pastes, Cem. Concr. Res. 88 (2016) 7-19. doi:10.1016/j.cemconres.2016.06.005.

[28] K. Scrivener, R. Snellings, B. Lothenbach, A Practical Guide to Microstructural Analysis of

[29] M.A.G. de la Torre, A.G. Bruque, S. Campo, J. Aranda, The superstructure of C3S from synchrotron and neutron powder diffraction and its role in quantitative phase analyses, Cem. Concr. Res. 32 (2002) 1347-1356.

754 [30] J.W. Mondal, P. Jeffery, The crystal structure of tricalcium aluminate, Ca3Al2O6, Acta

[31] S. Colville, A.A. Geller, The crystal structure of brownmillerite, Ca2FeAlO5, Acta Crystallogr.

[32] J.J. Chen, J.J. Thomas, H.F.W. Taylor, H.M. Jennings, Solubility and structure of calcium silicate

[33] R. Wartchow, Learnt profile"-Methode(LP) fuer Calcit und Vergleich mit der "Background peak

[34] H.E. Petch, The hydrogen positions in portlandite, $\mathrm{Ca}(\mathrm{OH}) 2$, as indicated by the electron distribution, Acta Crystallogr. 14 (1961) 950-957.

[35] J. Goetz-Neunhoeffer, F. Neubauer, Refined ettringite (Ca6Al2(SO4)3 (OH)12*26(H2O)) 
structure for quantitative X-ray diffraction analysis, Powder Diffr. (2006) 4-11.

766 [36] R. Allmann, Die Doppelschichtstruktur der plaettchenfoermigen Calcium-Aluminium-H Salze am Beispiel des (Ca O)3 A12 O3 Ca S O4 (H2 O)12, Neues Jahrb. Fuer Mineral. Monatshefte. (1968) 140-144.

[37] H. Runcevski, T. Dinnebier, R.E. Magdysyuk, O.V. Poellmann, Crystal structures of calcium

[38] O. Francois, M. Renaudin, G. Evrard, A cementitious compound with composition 3CaO.A12O3.CaCO3.11H2O, Acta Crystallogr. Sect. C Cryst. Struct. Commun. 54 (1998) $1214-1217$.

[39] A.G. Nord, Refinement of the crystal structure of thenardite, Na2SO4 (V), Acta Chem. Scand. 27 (1973) 814-822.

[40] G. Effenberger, H. Kirfel, A. Will, Untersuchungen zur Elektronendichteverteilung im Dolomit $\mathrm{CaMg}(\mathrm{CO} 3) 2$, Tschermaks Mineral. Und Petrogr. Mitteilungen. 31 (1983) 151-164.

[41] J.D. Jorgensen, Compression mechanisms in alpha-quartz structures -SiO2 and GeO2, J. Appl.

$781 \quad$ [42] K. Cromer, D.T. Herrington, The structures of anatase and rutile, J. Am. Chem. Soc. 77 (1955) $4708-4709$.

[43] R.P. Salvador, S.H.. Cavalaro, R. Monte, A.D. De, Relation between chemical processes and mechanical properties of sprayed cementitious matrices containing accelerators, Cem. Concr. Compos. 79 (2017) 1-40. doi:10.1016/j.cemconcomp.2017.02.002.

[44] R.P. Salvador, S.H.. Cavalaro, M. Cincotto, A.D. Figueiredo, Parameters controlling early age hydration of cement pastes containing accelerators for sprayed concrete, Cem. Concr. Res. J. 89

789 [45] B.M. Gassó, Impact of alkali salts on the kinetics and microstructural development of cementitious systems, ÉCOLE POLYTECHNIQUE FÉDÉRALE DE LAUSANNE, 2015.

791 [46] A. Kumar, Modelling hydration kinetics of cementitous systems, Ecole Polytechnique Fédérale de Lausanne, 2012.

793 [47] J. Skalny, J. Marchand, I. Odler, Sulfate Attack on Concrete, Spon Press, 2002.

794 [48] N. Crammond, Examination of mortar bars containing varying percentages of coarsely 
crystalline gypsum as aggregate., Cem. Concr. Res. 14 (1984) 225-230.

796 [49] T. Ikumi, S. Cavalaro, I. Segura, C. Goodier, S. Austin, Simplified analytical assessment of

[50] T. Ikumi, S.H.P. Cavalaro, I. Segura, A. Aguado, Alternative methodology to consider damage and expansions in external sulfate attack modeling, Cem. Concr. Res. 63 (2014) 105-116. doi:10.1016/j.cemconres.2014.05.011.

804

[51] W. Dosch, H. zur Strassen, No Title, Zement-Kalk-Gips. 20 (1967) 392.

805

[52] G. Li, P. Le Bescop, M. Moranville, The U-Phase formation in cement-based systems containing

806 high amounts of Na2SO4, Cem. Concr. Res. 26 (1996) 27-33.

\section{Appendix A. Appendix}

Results of length variation of all the mixtures obtained by periodic measures are shown from

Table A.1 Length Variation (x $\left.10^{-3}\right)$ of the mixtures from 0 to 98 days.

\begin{tabular}{lcccccccccc}
\hline \multirow{2}{*}{ Mixtures } & \multicolumn{10}{c}{ Time(days) } \\
\cline { 2 - 11 } & 0 & 7 & 14 & 21 & 28 & 42 & 56 & 70 & 84 & 98 \\
\hline CI_REF_7 & 0 & -0.021 & 0.019 & 0.033 & -0.006 & -0.017 & -0.078 & -0.082 & -0.090 & -0.077 \\
CI_REF_28 & 0 & -0.002 & -0.007 & -0.016 & -0.041 & -0.045 & -0.050 & -0.054 & -0.047 & -0.031 \\
CI_AF060_5\%_7 & 0 & 0.101 & 0.121 & 0.131 & 0.163 & 0.226 & 0.254 & 0.292 & 0.275 & 0.292 \\
CI_AF060_5\%_28 & 0 & 0.016 & 0.042 & 0.083 & 0.108 & 0.121 & 0.130 & 0.233 & 0.260 & 0.280 \\
CI_AF040_5\%_28 & 0 & 0.042 & 0.055 & 0.061 & 0.080 & 0.085 & 0.057 & 0.056 & 0.052 & 0.100 \\
CI_AR130_3\%_7 & 0 & 0.182 & 0.201 & 0.254 & 0.219 & 0.241 & 0.253 & 0.283 & 0.284 & 0.282 \\
CI_AR130_3\%_28 & 0 & 0.034 & 0.036 & 0.052 & 0.079 & 0.090 & 0.126 & 0.099 & 0.085 & 0.096 \\
CI_AR080_3\%_28 & 0 & 0.081 & 0.148 & 0.195 & 0.221 & 0.396 & 0.923 & 1.534 & 2.137 & 3.738 \\
\hline CII_AR080_3\%_7 & 0 & 0.153 & 0.232 & 0.736 & 2.144 & 7.846 & - & - & - & - \\
CII_AR080_3\%_28 & 0 & 0.069 & 0.126 & 0.155 & 0.228 & 0.585 & 0.613 & 0.757 & 0.800 & 1.127 \\
CII_REF_7 & 0 & 0.065 & 0.140 & 0.138 & 0.107 & 0.182 & 0.158 & 0.127 & 0.119 & 0.109 \\
CII_REF_28 & 0 & -0.032 & -0.002 & -0.005 & -0.041 & -0.028 & -0.081 & -0.064 & -0.063 & -0.056 \\
\hline
\end{tabular}




\begin{tabular}{lcccccccccc}
\hline \multicolumn{1}{c}{ Mixtures } & \multicolumn{10}{c}{ Time (days) } \\
\cline { 2 - 11 } & 112 & 126 & 140 & 154 & 168 & 182 & 210 & 238 & 266 & 294 \\
\hline CI_REF_7 & -0.035 & -0.082 & -0.057 & -0.071 & -0.067 & -0.071 & -0.109 & -0.133 & -0.088 & -0.052 \\
CI_REF_28 & -0.036 & -0.040 & -0.058 & -0.043 & -0.045 & -0.073 & -0.104 & -0.107 & -0.055 & -0.056 \\
CI_AF060_5\%_7 & 0.330 & 0.379 & 0.457 & 0.544 & 0.612 & 0.698 & 0.834 & 1.071 & 1.314 & 1.507 \\
CI_AF060_5\%_28 & 0.314 & 0.293 & 0.307 & 0.310 & 0.301 & 0.291 & 0.312 & 0.334 & 0.334 & 0.355 \\
CI_AF040_5\%_28 & 0.134 & 0.152 & 0.173 & 0.191 & 0.201 & 0.213 & 0.242 & 0.259 & 0.357 & 0.435 \\
CI_AR130_3\%_7 & 0.289 & 0.310 & 0.341 & 0.522 & 0.667 & 0.872 & 0.978 & 1.294 & 1.726 & 2.180 \\
CI_AR130_3\%_28 & 0.151 & 0.167 & 0.171 & 0.171 & 0.217 & 0.217 & 0.333 & 0.413 & 0.607 & 0.881 \\
CI_AR080_3\%_28 & 6.001 & 7.101 & - & - & - & - & - & - & - & - \\
\hline CII_AR080_3\%_7 & - & - & - & - & - & - & - & - & - & - \\
CII_AR080_3\%_28 & 1.541 & 2.082 & 2.704 & 3.380 & - & - & - & - & - & - \\
CII_REF_7 & 0.157 & 0.200 & 0.211 & 0.236 & 0.170 & 0.204 & 0.219 & 0.185 & 0.188 & 0.308 \\
CII_REF_28 & -0.032 & 0.004 & -0.016 & -0.075 & -0.064 & -0.057 & -0.087 & -0.124 & -0.032 & -0.050 \\
\hline
\end{tabular}

820 Table A.3 Length Variation $\left(\times 10^{-3}\right)$ of the mixtures from 294 to 400 days.

\begin{tabular}{lcccc}
\hline \multirow{2}{*}{ Mixtures } & \multicolumn{5}{c}{ Time (days) } \\
\cline { 2 - 5 } & 322 & 350 & 378 & 400 \\
\hline CI_REF_7 & -0.061 & -0.043 & -0.026 & -0.049 \\
CI_REF_28 & -0.062 & -0.084 & -0.107 & -0.101 \\
C__AF060_5\%_7 & 1.670 & 1.872 & 1.977 & 2.081 \\
CI_AF060_5\%_28 & 0.390 & 0.398 & 0.405 & 0.507 \\
CI_AF040_5\%_28 & 0.515 & 0.574 & 0.633 & 0.730 \\
CI_AR130_3\%_7 & 2.475 & 2.954 & 3.136 & 3.317 \\
CI_AR130_3\%_28 & 0.985 & 1.752 & 2.519 & 2.674 \\
CI_AR080_3\%_28 & - & - & - & - \\
\hline CII_AR080_3\%_7 & - & - & - & - \\
CII_AR080_3\%_28 & - & - & - & - \\
CIIREF_7 & 0.385 & 0.385 & 0.421 & 0.387 \\
CII_REF_28 & -0.048 & -0.051 & -0.054 & 0.171 \\
\hline
\end{tabular}

822

823 